\title{
Validation of 3-D basin structure models for long-period ground motion simulation in the Osaka basin, western Japan
}

\author{
Asako Iwaki • Tomotaka Iwata
}

Received: 12 April 2007 / Accepted: 2 January 2008 / Published online: 21 February 2008

(C) The Author(s) 2008

\begin{abstract}
We studied the applicability of two types of existing three-dimensional (3-D) basin velocity structure models of the Osaka basin, western Japan for long-period ground motion simulations. We synthesized long-period (3-20 s) ground motions in the Osaka basin during a M6.5 earthquake that occurred near the hypothetical Tonankai earthquake source area, approximately $200 \mathrm{~km}$ from Osaka. The simulations were performed using a 3-D finite-difference method with nonuniform staggered grids using the two basin velocity structure models. To study the ground motion characteristics inside the basin, we evaluated the wave field inside the basin using the transfer functions derived from the synthetics at the basin and a reference rock site outside the basin. The synthetic waveforms at the basin site were obtained by a convolution of the calculated transfer function and the observed waveform at the reference rock site.

First, we estimated the appropriate $Q$ values for the sediment layers. Assuming that the $Q$ value depends on the $\mathrm{S}$ wave velocity $V_{\mathrm{S}}$ and period $T$, it was set to $Q=\left(1 / 3 V_{\mathrm{S}}\right)\left(T_{0} / T\right)$ where $V_{\mathrm{S}}$ is in $\mathrm{m} / \mathrm{s}$ and the reference
\end{abstract}

\footnotetext{
A. Iwaki $(\bowtie) \cdot T$. Iwata

Disaster Prevention Research Institute,

Kyoto University,

Gokasho,

Uji, Kyoto 611-0011, Japan

e-mail: iwaki@egmdpri01.dpri.kyoto-u.ac.jp

T. Iwata

e-mail: iwata@egmdpri01.dpri.kyoto-u.ac.jp
}

period $T_{0}$ is $3.0 \mathrm{~s}$. Second, we compared the synthetics and the observations using waveforms and pseudovelocity response spectra, together with a comparison of the velocity structures of the two basin models. We also introduced a goodness-of-fit factor to the pseudovelocity response spectra as an objective index. The synthetics of both the models reproduced the observations reasonably well at most of the stations in the central part the basin. At some stations, however, especially where the bedrock depth varies sharply, there were noticeable discrepancies in the simulation results of the models, and the synthetics did not accurately reproduce the observation. Our results indicate that the superiority of one model over the other cannot be determined and that an improvement in the basin velocity structure models based on simulation studies is required, especially along the basin edges. We also conclude that our transfer function method can be used to examine the applicability of the basin velocity structure models for longperiod ground motion simulations.

Keywords 3-D basin structure model $\cdot$ Long-period ground motion $\cdot$ Waveform simulation

\section{Introduction}

Osaka area, western Japan, is located in a sedimentary basin that is approximately $200 \mathrm{~km}$ from the Nankai trough where large M8-class interplate earthquakes 
have repeatedly occurred. The Headquarters for Earthquake Research Promotion has estimated that the long-term occurrence potentials of the subsequent earthquakes (Tonankai and Nankai) at the trough are from $50 \%$ to $70 \%$ within 30 years from 2007 (http:// www.jishin.go.jp/main/index-e.html). Several megacities, such as Osaka and Kobe, are situated in the Osaka sedimentary basin; these cities have many skyscraper buildings, long-span bridges, and oil tanks, which have not yet experienced any long-period ground motions due to the M8-class earthquakes. During the 2003 Tokachi-oki earthquake, many large oil tanks in Hokkaido, northern Japan were damaged because of the sloshing of the liquid inside the tanks caused by long-period ground motions, although they were $250 \mathrm{~km}$ away from the source area (Koketsu et al. 2005). This event convinced us that M8-class earthquakes are very likely to inflict long-period ground motions on deep sedimentary sites. Therefore, it is one of the important and urgent issues to be addressed for earthquake disaster prevention to predict the long-period ground motions in the sedimentary area during hypothetical large earthquakes in the Nankai trough.

For accomplishing accurate strong ground motion predictions and estimations, not only the source model but also a propagation path velocity structure model is necessary (e.g., Kagawa et al. 1998a, b). As far as we
Fig. 1 Map of the target area. A geographical map of the Osaka basin area is shown

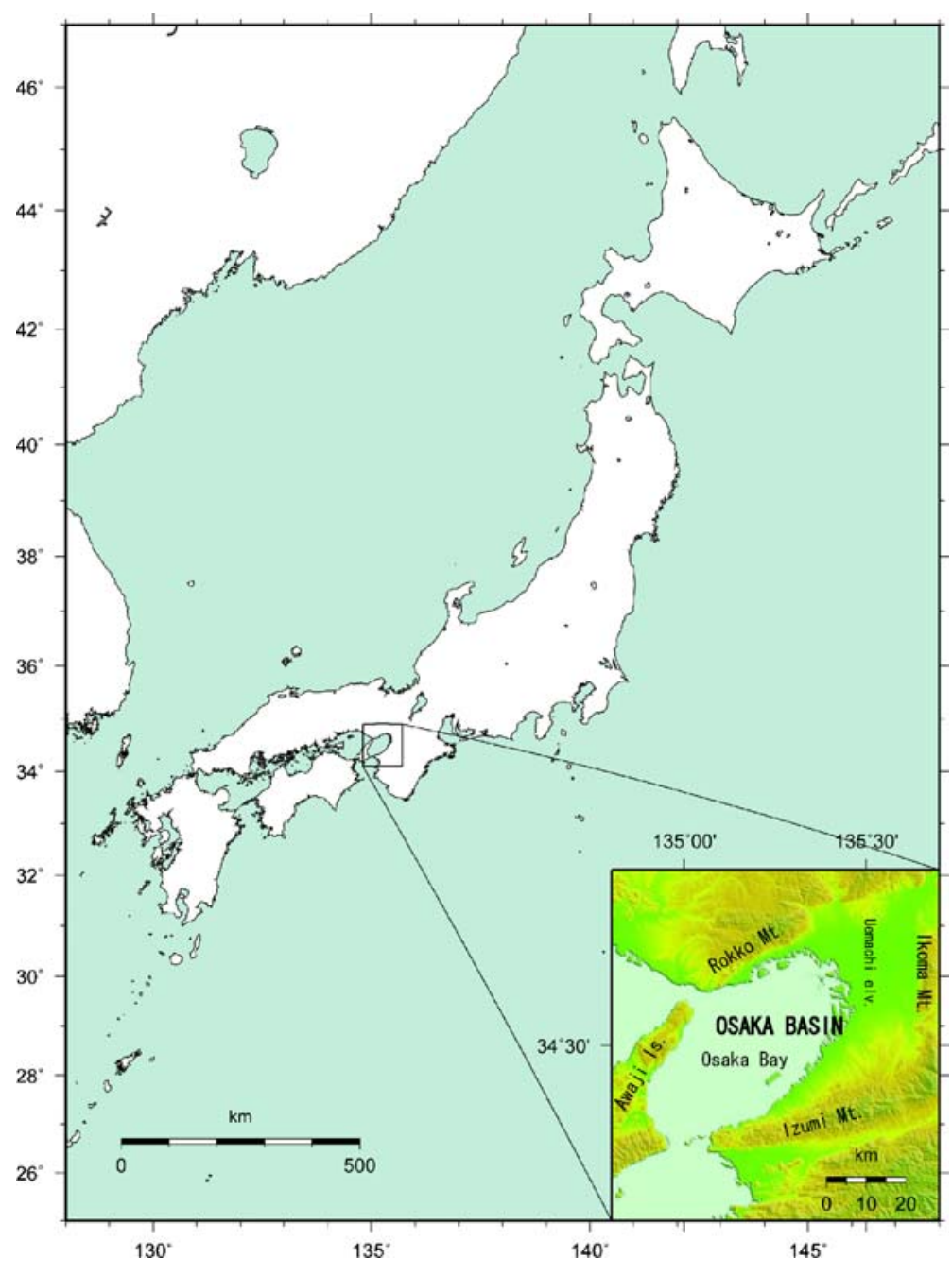


understand, large basin structures strongly affect the generation of long-period ground motions. The Osaka basin has been well investigated by many seismic exploration surveys, boring information, microtremor explorations, and gravity explorations, which have contributed to the consequent construction of the detailed three-dimensional (3-D) basin velocity structure models (e.g., Kagawa et al. 2004a; Horikawa et al. 2003). So far, these 3-D basin models have been validated by comparing the synthetic and observed
Fig. 2 Contour map of the bedrock depth at the Osaka basin obtained from a model A (Kagawa et al. 2004) and $\mathbf{b}$ model B (Horikawa et al. 2003). The closed triangles represent the locations of the strong motion stations, and the closed square represents the reference rock station (CHY) with the station names used in this study. The stations used in Figs. 6 and 7 are underlined
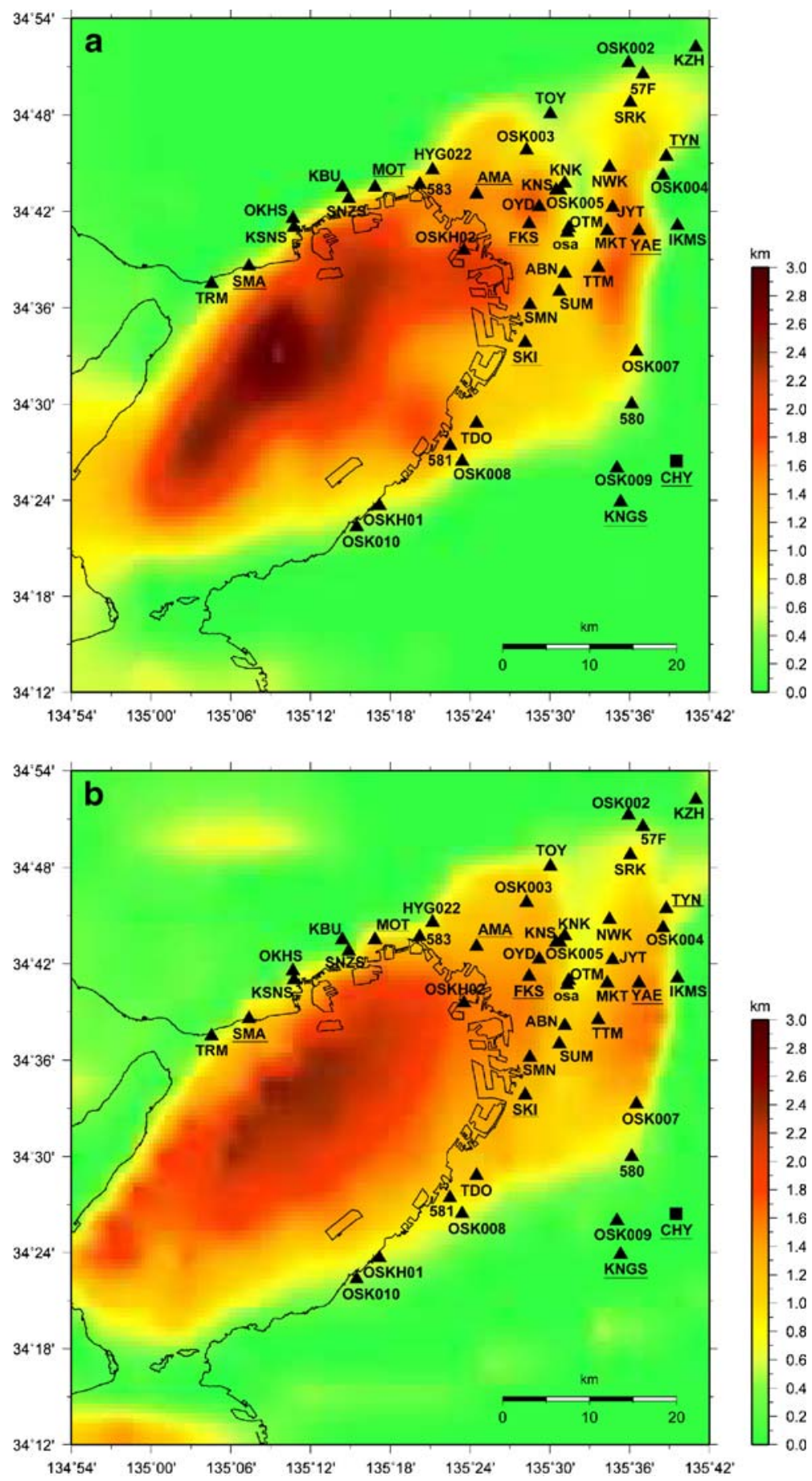
Table 1 List of strong motion stations used in this study

\begin{tabular}{|c|c|c|c|}
\hline Station code & Longitude & Latitude & Organization \\
\hline $\mathrm{ABN}$ & 135.5190 & 34.6360 & CEORKA \\
\hline AMA & 135.4080 & 34.7180 & CEORKA \\
\hline SKI & 135.4690 & 34.5640 & CEORKA \\
\hline FKS & 135.4740 & 34.6870 & CEORKA \\
\hline MKT & 135.5720 & 34.6800 & CEORKA \\
\hline YAE & 135.6120 & 34.6800 & CEORKA \\
\hline TDO & 135.4080 & 34.4800 & CEORKA \\
\hline SRK & 135.6010 & 34.8130 & CEORKA \\
\hline TOY & 135.5010 & 34.8010 & CEORKA \\
\hline MOT & 135.2810 & 34.7250 & CEORKA \\
\hline $\mathrm{KBU}$ & 135.2400 & 34.7250 & CEORKA \\
\hline SMA & 135.1230 & 34.8130 & CEORKA \\
\hline TRM & 135.0760 & 34.6250 & CEORKA \\
\hline HSD & 135.9120 & 34.5400 & CEORKA \\
\hline Osa & 135.5220 & 34.6780 & DPRI \\
\hline KNK & 135.5190 & 34.7290 & OCWB \\
\hline KNS & 135.5080 & 34.7220 & OCWB \\
\hline NWK & 135.5750 & 34.7460 & OCWB \\
\hline TYN & 135.6460 & 34.7570 & OCWB \\
\hline OYD & 135.4870 & 34.7050 & OCWB \\
\hline TTM & 135.5610 & 34.6420 & OCWB \\
\hline JYT & 135.5790 & 34.7040 & OCWB \\
\hline OTM & 135.5240 & 34.6830 & OCWB \\
\hline SMN & 135.4750 & 34.6030 & OCWB \\
\hline SUM & 135.5120 & 34.6170 & OCWB \\
\hline $\mathrm{KZH}$ & 135.6830 & 34.8700 & OCWB \\
\hline SNZS & 135.2480 & 34.7130 & Denkyo \\
\hline IKMS & 135.6600 & 34.6853 & Denkyo \\
\hline KNGS & 135.5889 & 34.3983 & Denkyo \\
\hline KSNS & 135.1794 & 34.6831 & Denkyo \\
\hline OKHS & 135.1781 & 34.6925 & Denkyo \\
\hline OSK002 & 135.5986 & 34.8541 & K-NET \\
\hline OSK003 & 135.4711 & 34.7636 & K-NET \\
\hline OSK004 & 135.6422 & 34.7372 & K-NET \\
\hline OSK005 & 135.5130 & 34.7220 & K-NET \\
\hline OSK007 & 135.6086 & 34.5544 & K-NET \\
\hline OSK008 & 135.3902 & 34.4405 & K-NET \\
\hline OSK009 & 135.5844 & 34.4333 & K-NET \\
\hline OSK010 & 135.2577 & 34.3722 & K-NET \\
\hline HYG022 & 135.3530 & 34.7430 & K-NET \\
\hline OSKH01 & 135.2864 & 34.3944 & KiK-net \\
\hline OSKH02 & 135.3924 & 34.6595 & KiK-net \\
\hline 580 & 135.6030 & 34.5000 & JMA \\
\hline $57 \mathrm{~F}$ & 135.6170 & 34.8420 & JMA \\
\hline 583 & 135.3370 & 34.7280 & JMA \\
\hline 581 & 135.3750 & 34.4570 & JMA \\
\hline $\mathrm{CHY}$ & 135.6590 & 34.4390 & CEORKA \\
\hline
\end{tabular}

ground motions from moderate size local events. These results showed some agreement, especially on S wave amplification and duration characteristics. However, the validations were restricted to a period range of approximately $2 \mathrm{~s}$ because the events lacked the power to generate ground motions in the longer-period range. On September 5, 2004, two M7-class events (the 2004 off the Kii peninsula earthquake) followed by a sequence of several M6-class aftershocks occurred at the outer rise of the subducting Philippine Sea Plate. The epicenters of the earthquake sequence were near the source region of the hypothetical Tonankai earthquake (e.g., Bai et al. 2006). The ground motions for periods longer than $3 \mathrm{~s}$ were well recorded at the sedimentary sites during these events (e.g., Iwata and Asano 2005; Yamada and Iwata 2005).

In this paper, we attempted to validate the existing basin velocity structure models to estimate their applicability of periods of $3 \mathrm{~s}$ or longer for strong motion predictions. We collected as many observed ground motion data of this earthquake sequence as possible from various organizations and compared them with the synthetics of the 3-D basin velocity structure models. In the process, we discussed the site characteristics of the ground motion observed in the Osaka basin. We also estimated the appropriate $Q$ values for the sediment layers required to reproduce the duration of long-period ground motions.

\section{Osaka basin velocity structure models}

The location of the Osaka basin is shown in Fig. 1. The Osaka basin is surrounded by the Rokko Mountains (North), Ikoma Mountains (East), Izumi Mountains (South), and Awaji Island (West) and has a roughly ellipsoid shape with a length of $60 \mathrm{~km}$ in the NE-SW direction and a width of $40 \mathrm{~km}$ in the NW$\mathrm{SE}$ direction. Kagawa et al. first compiled the seismic reflection and refraction survey results and the boring information into a dataset, from which they derived a $3-D$ velocity structure model of the sediment. The $\mathrm{S}$ wave velocities in the sediments were estimated by microtremor array measurements. Each point, whose seismic bedrock depth was obtained from the exploration surveys, was set as a control point. Next, they interpolated and extrapolated the seismic bedrock depth information at the control points using a twodimensional third-order B-spline function (e.g., 
Fig. 3 Model area for the calculation. A finer mesh in the northwestern rectangular portion including the Osaka basin for the FDM calculation is used. The epicenter of the largest aftershock is shown with its source mechanism. The closed circles indicate the strong motion stations inside and around the Osaka basin

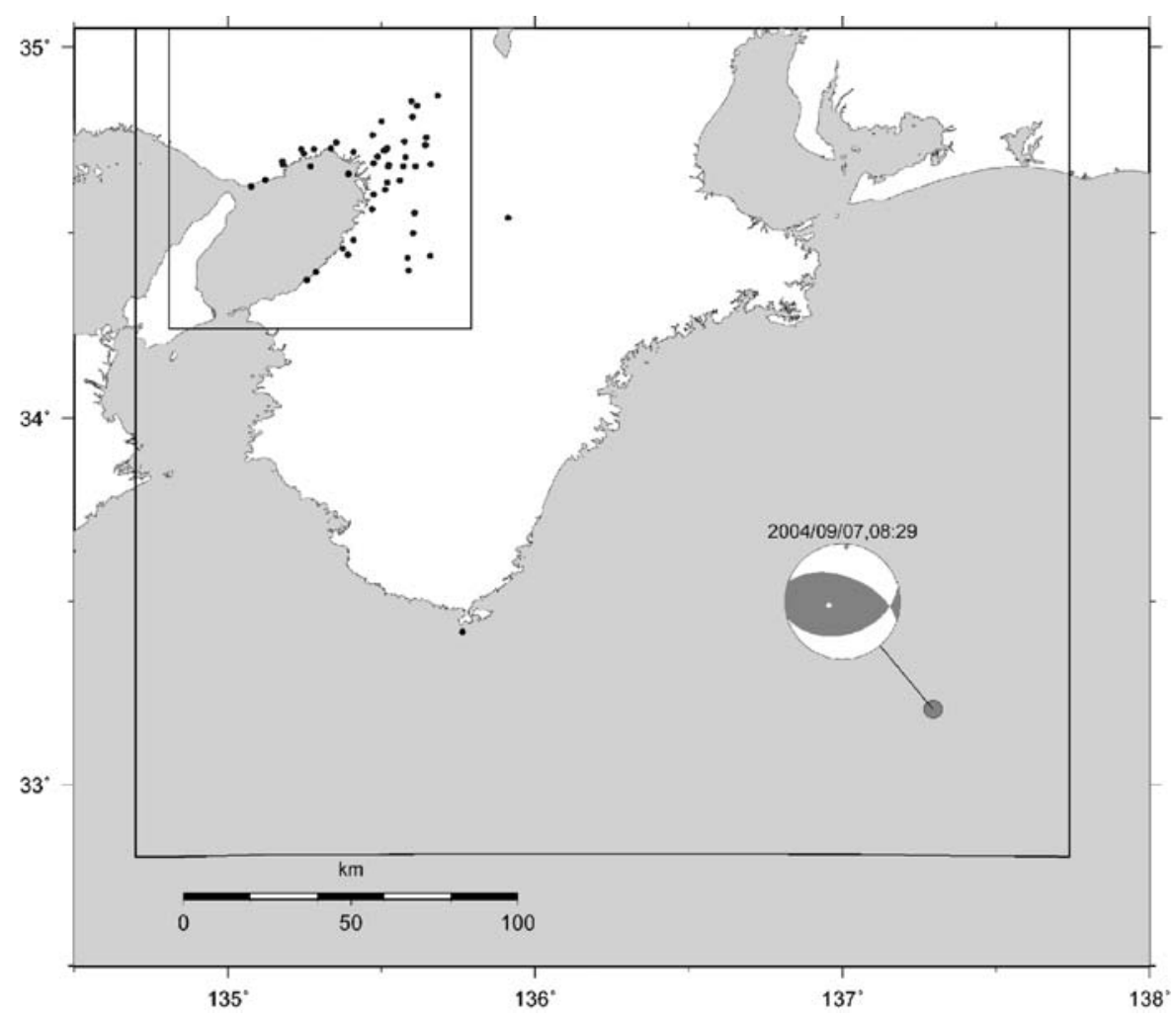

Koketsu and Higashi 1992) to represent the seismic bedrock depth geometry of the basin. They assumed that the sediment consists of three layers whose interface depths are proportional to the seismic bedrock depth. As the spline model is easily modifiable by adding new control points, they have been continuously adopting new exploration information to improve their basin velocity structure model (Kagawa et al. 1993; Miyakoshi et al. 1997; Miyakoshi et al. 1999; Iwata et al. 2006, 2008). Their model is extremely compact as it consists of only the spline function coefficients; however, it has a disadvantage

Table 2 List of the model parameters for the crustal structure

\begin{tabular}{ccccc}
\hline & $\begin{array}{l}V_{\mathrm{P}} \\
\mathrm{Km} / \mathrm{s}\end{array}$ & $\begin{array}{l}V_{\mathrm{S}} \\
\mathrm{km} / \mathrm{s}\end{array}$ & $\begin{array}{l}\rho \\
\mathrm{g} / \mathrm{cm}^{3}\end{array}$ & $\begin{array}{l}\text { Depth } \\
\mathrm{km}\end{array}$ \\
\hline 1 & 5.40 & 3.20 & 2.7 & 3.1 \\
2 & 6.00 & 3.70 & 2.8 & 15 \\
3 & 6.70 & 3.90 & 2.9 & 35 \\
4 & 7.70 & 4.45 & 3.1 & 50 \\
\hline
\end{tabular}

Kagawa et al. 2004a, b in that the sudden lateral changes in the interfaces cannot be described.

Another 3-D velocity model by Horikawa et al. (2002, 2003) permits horizontal discontinuities in the sediment layers and takes into account of the information of active faults in this region and the horizontal velocity structure boundary. They assigned $\mathrm{P}$ and $\mathrm{S}$ wave velocities to grid points distributed in three dimensions with a spacing of $100 \mathrm{~m}$ for performing the calculations using a finite-difference method. The $\mathrm{P}$ wave velocity was derived from seismic exploration surveys, and the $\mathrm{S}$ wave velocity

Table 3 Model parameters of the Osaka sedimentary layers for model A

\begin{tabular}{lllll}
\hline & $\begin{array}{l}V_{\mathrm{P}} \\
\mathrm{Km} / \mathrm{s}\end{array}$ & $\begin{array}{l}V_{\mathrm{S}} \\
\mathrm{Km} / \mathrm{s}\end{array}$ & $\begin{array}{l}\rho \\
\mathrm{g} / \mathrm{cm}^{3}\end{array}$ & $\begin{array}{l}\text { Depth } \\
\mathrm{km}\end{array}$ \\
\hline 1 & 1.60 & 0.35 & 1.7 & $0.193 h$ \\
2 & 1.80 & 0.55 & 1.8 & $0.472 h$ \\
3 & 2.50 & 1.00 & 2.1 & $h$ \\
\hline
\end{tabular}

Kagawa et al. 2004a, b 
Table 4 Source parameters for the largest aftershock used in this study

Source parameters for the largest aftershock

\begin{tabular}{ll}
\hline Latitude, longitude & $\mathrm{N} 33.209^{\circ}, \mathrm{E} 137.293^{\circ}$ \\
Strike, dip, slip & $272^{\circ}, 49^{\circ}, 97^{\circ}$ \\
Mo $(\mathrm{N} / \mathrm{m})$ & $6 \times 10^{18}$
\end{tabular}

was assumed using the relationship between the $\mathrm{P}$ and S wave velocities (Gassmann 1951). Consequently, the velocities in the sedimentary layer generally increase gradually in the depth direction. This relationship between the $\mathrm{P}$ and $\mathrm{S}$ wave velocities was also applied to the velocities of the bedrock.
They assumed the $\mathrm{P}$ wave velocity of the bedrock to be $5.5 \mathrm{~km} / \mathrm{s}$ and derived an $\mathrm{S}$ wave velocity of $2.75 \mathrm{~km} / \mathrm{s}$, instead of $3.2 \mathrm{~km} / \mathrm{s}$ that is generally used for the hypocenter determination of the superficial layer of the crust in this region. The seismic bedrock depth distributions in the sediments for both the models are shown in Fig. 2. Hereafter, we will refer to the basin velocity structure model developed by Kagawa et al. (2004a) as model A and that developed by Horikawa et al. (2003) as model B. Macroscopically, the models are similar to each other. However, model B includes the abrupt change in the basin shape, e.g., at the northern (Rokko) and the eastern (Ikoma) basin edges and the Uemachi fault beneath the central part of the basin. We compared the longperiod ground motion characteristics from the simulations obtained using these two models.
Fig. 4 Comparison of the depth distributions of the $\mathrm{S}$ wave velocities of the two models at stations $\mathrm{CHY}$, FKS, SUM, OSKH02, TYN, and MOT. The depth distributions from the surface up to $3 \mathrm{~km}$ depth are shown. The open circles and plus signs indicate the $\mathrm{S}$ wave velocity at each grid point of model A and model $\mathrm{B}$ for the 3-D FDM calculations, respectively
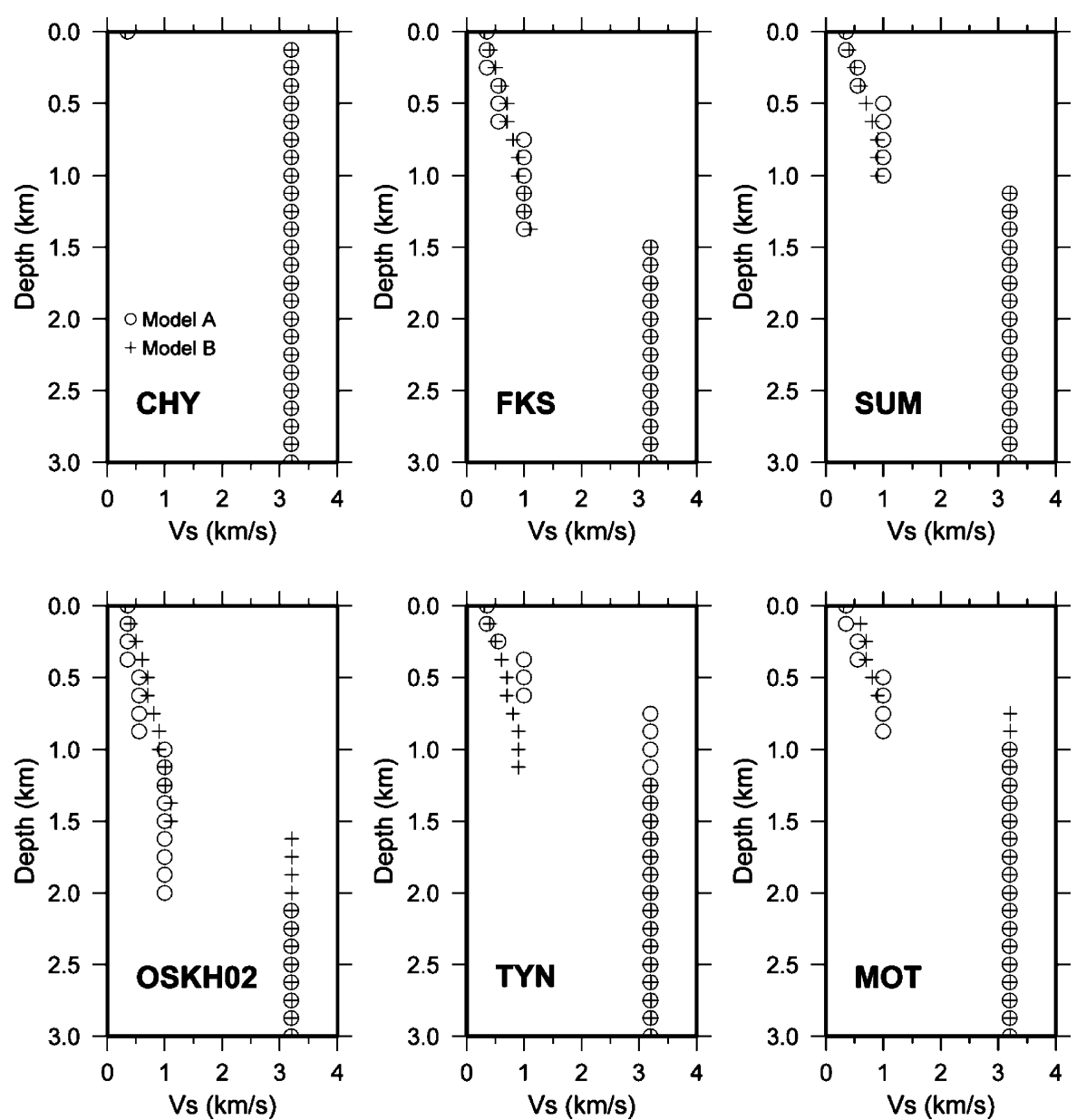


\section{Ground motion data of the 2004 off the Kii peninsula earthquake in and around the Osaka basin}

On September 5, the 2004 off the Kii peninsula earthquake occurred in the neighborhood of the source region of the hypothetical Tonankai earthquake. A preshock ( $\left.\mathrm{M}_{\mathrm{JMA}} 7.1\right)$, mainshock $\left(\mathrm{M}_{\mathrm{JMA}}\right.$ 7.4), and several M6-class aftershocks were observed in sequence. The Osaka basin is located approximately $200 \mathrm{~km}$ from the epicenters of this event sequence. Iwata and Asano (2005) and Miyake and Koketsu (2005) reported that long-period ground motions were observed at the Osaka basin sites. In this source region, only few earthquakes of M6 and larger that could generate long-period ground motions inside the basin had occurred after the 1944 Tonankai and the 1946 Nankai earthquakes. Therefore, the ground motion records obtained from this off the Kii peninsula earthquake are extremely valuable and appropriate for estimating the characteristics of long-period ground motions of the Osaka basin for the subsequent Tonankai and Nankai earthquakes. Because our aim was to evaluate the applicability of the basin velocity structure models to the ground motion simulations by comparing with the observed seismograms, the higher the number of observation sites we used, the better the evaluation we expected. We collected the seismograms of this event sequence provided by the K-NET (Kinoshita 1998) and KiK-net (Aoi et al. 2001) maintained by the National
Research Institute for Earth Science and Disaster Prevention (NIED), the seismic intensity observation network of Japan Meteorological Agency (JMA), the Committee of Earthquake Observation and Research in the Kansai Area (CEORKA; Kagawa et al. 2004b), and the strong motion network project of 10 electric power companies (Denkyo). We also collected the waveforms of the Osaka City Waterworks Bureau (OCWB) that observed ground motions at each waterworks area by a velocity-type strong motion seismograph. We examined the orientation of the seismograph of each waterworks area by comparing its horizontal particle motion at a long-period range ( $>20 \mathrm{~s}$ ) with that of a neighboring CEORKA site and corrected the orientation of the horizontal components following the method by Kato et al. (2001). We used 47 ground motion data in total from 4 rock site stations and 43 basin site stations for this study. As mentioned in the next section, we used the largest aftershock event data to compare with the synthetics. The stations used in this study are shown in Fig. 2, and the station positions are listed in Table 1.

\section{Waveform simulation}

We conducted a long-period ground motion simulation of the largest aftershock (September 7, 2004, 08:29 JST, $\mathrm{M}_{\mathrm{JMA}}$ 6.4) with the aim of reproducing the characteristics of the observed long-period ground motions. We chose this event among the others,
Fig. 5 Comparison of the synthetic and observed velocity waveforms (bandpass filtered at 3-20 s) at FKS and 581 by model $A$ using different reference periods of $Q$ values. Left: east-west component; right: northsouth component

\section{FKS}
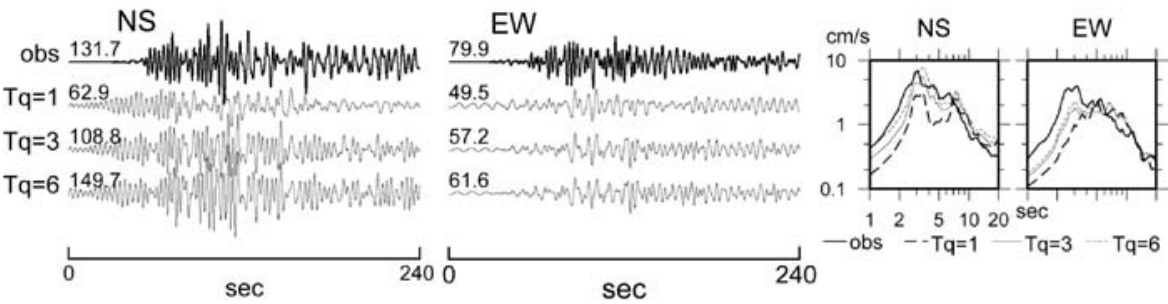

581
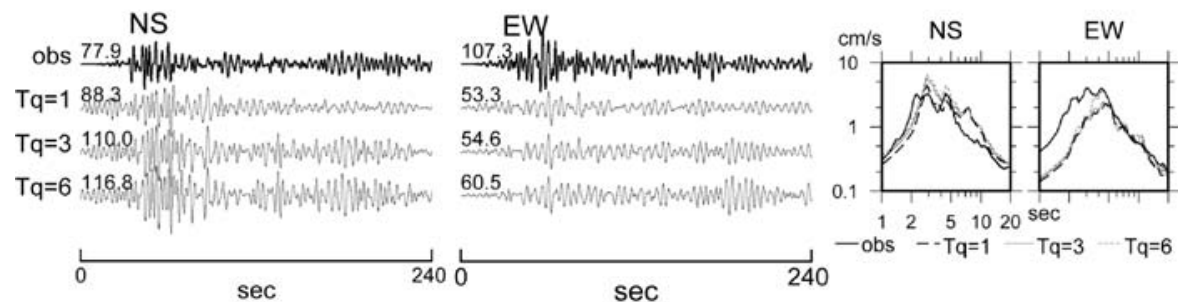
including the preshock and the mainshock (September 5, 19:07 and 23:57 JST, respectively), because we judged that its source time function is relatively simple and that it has generated long-period ground motions with a sufficient $S / N$ ratio. The computation was performed using the 3-D finite-difference method with nonuniform staggered grids (Pitarka 1999). Figure 3 shows the model area of the computation. The basin velocity structure models are put into the northwestern region of the model area. The entire model area size is $260 \mathrm{~km}(\mathrm{EW}) \times 290 \mathrm{~km}(\mathrm{NS}) \times$
$60 \mathrm{~km}$ (depth), and the basin portion size is $90 \mathrm{~km}$ $(\mathrm{EW}) \times 90 \mathrm{~km}(\mathrm{NS}) \times 3 \mathrm{~km}$ (depth). The crustal structure outside the basin is represented by a onedimensional (1-D) velocity structure with the model parameters referring to Iwata et al. (2006). The model parameters of the crustal velocity structure and the basin velocity structure parameters for model A are listed in Tables 2 and 3. Although the original seismic bedrock $\mathrm{S}$ wave velocity for model B was $2.75 \mathrm{~km} / \mathrm{s}$, as mentioned before, we set the seismic bedrock $\mathrm{S}$ wave velocity as $3.2 \mathrm{~km} / \mathrm{s}$ for both the models so that
Fig. 6 Comparison of the observed velocity waveforms (thick line; top) and the synthetic velocity waveforms by model A (thin line; middle) and by model $\mathrm{B}$ (thin line; bottom) at stations $\mathrm{CHY}, \mathrm{KNGS}, \mathrm{ABN}$, AMA, YAE, OSK007, KBU, and SMA. The waveforms are bandpass filtered at 3-20 s. The number beside each trace indicates the maximum amplitude in $\mathrm{cm} / \mathrm{s}$

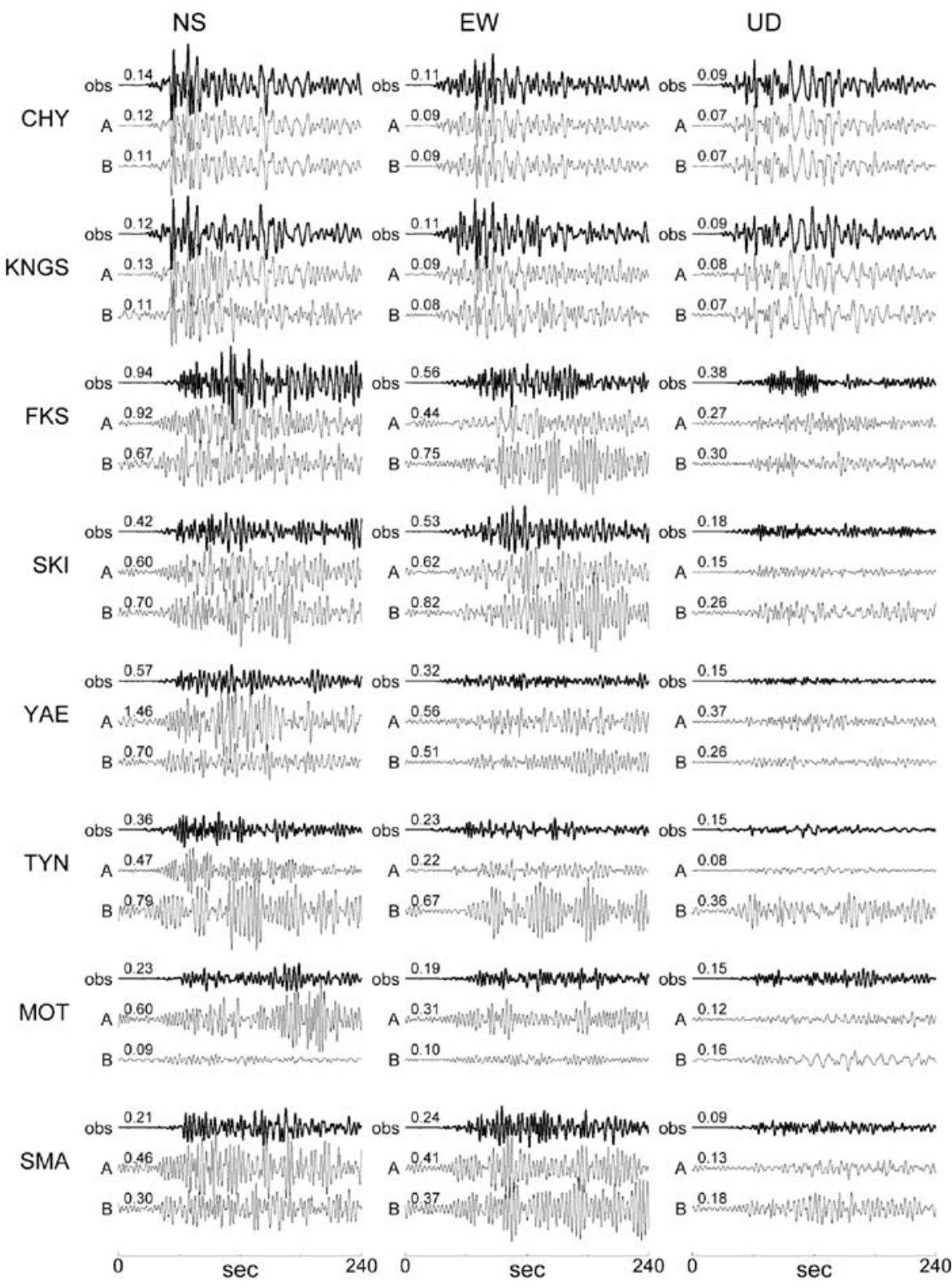


the input ground motions to the basin were identical to each other. The earthquake source was modeled as a double couple point source whose parameters are listed in Table 4. We adopted the epicenter determined by JMA and the source mechanism by F-net of NIED, and estimated the source duration and the source depth so as to fit the waveforms observed at CHY, a CEORKA rock site that is located southeast of the basin. The source duration and source depth were obtained as $3 \mathrm{~s}$ and $25 \mathrm{~km}$, respectively. Although there is a slight uncertainty about the source depth value obtained, it will not have a significant effect on the following discussion.

Because the calculation included periods down to $3 \mathrm{~s}$, the smallest grid size in the basin region of each model was set to $125 \mathrm{~m}$ with a minimum $\mathrm{S}$ wave velocity of $300 \mathrm{~m} / \mathrm{s}$ to avoid significant numerical dispersion. Figure 4 shows the comparisons of the $\mathrm{S}$ wave velocity depth profiles of the two models at several stations located in the basin. The difference between the $\mathrm{S}$ wave velocity profiles of the two models is relatively small at the stations located in the central part of the basin, such as FKS and SUM with the exception of OSKH02 where there exists a major discrepancy in the bedrock depths. On the other hand, the difference is larger at many stations located near the northern edge of the basin, such as TYN and MOT.

Past studies on the ground motion simulations of the 2004 off the Kii peninsula earthquake records have pointed out the effect of the sedimentary wedge produced by the subduction of the Philippine Sea plate on the amplification of the long-period ground motion inside the Osaka basin (e.g., Yamada and Iwata 2005). In this paper, we used a very simple 1-D crustal velocity structure model outside the basin region. To focus on the wave propagation character-
Fig. 7 Comparison of the pseudovelocity response spectra (pSv, $h=5 \%$ ) for the observation (black line) and the synthetics by model A (red line) and model B (blue line) on the north-south component (left column) and east-west component (right column)
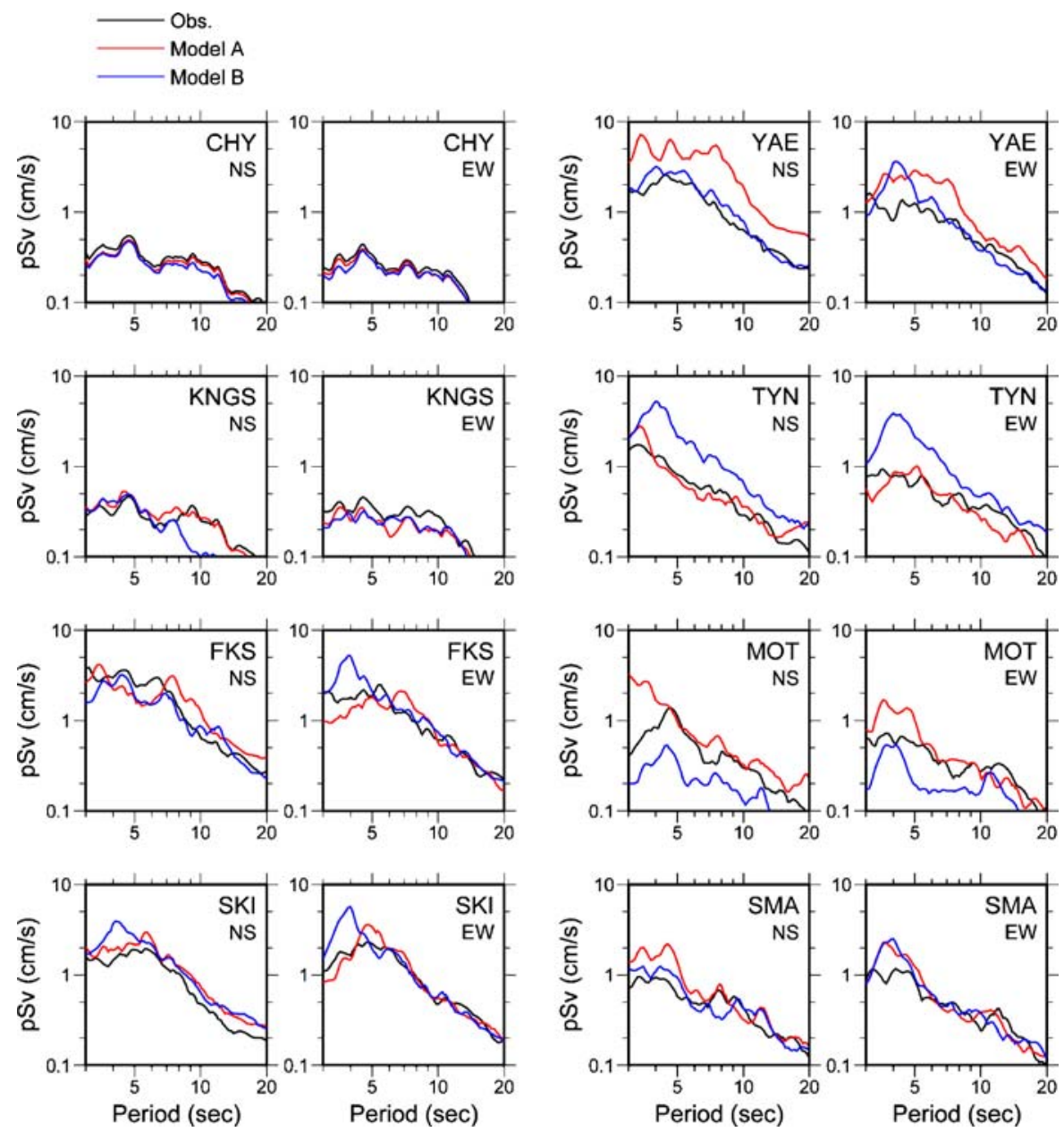
istics inside the basin, we reproduced the synthetic ground motions in the basin by the following method.

We defined a site-to-site relation or a transfer function between the ground motions of a basin site and a reference rock site near the Osaka basin. The waveform of a basin site $(i)$ can be expressed as a convolution of the waveform at the rock site (rock) and the transfer function. Thus:

$O_{i}(t)=T_{i}(t) * O_{\text {rock }}(t)$,

from observations and

$C_{i}(t)=T_{i}^{\prime}(t) * C_{\text {rock }}(t)$,

from simulations where $O(t)$ and $C(t)$ represent the waveforms, and $T(t)$ and $T^{\prime}(t)$ are the transfer functions for the observations and synthetics, respectively. Assuming that the calculated transfer function $T^{\prime}(t)$ is identical to the observed $T(t)$, the synthetic ground motion at a basin site is obtained by calculating a convolution of the calculated transfer function and the observed ground motion of the rock site, i.e., the synthetic waveform $S_{i}(t)$ is:

$$
\begin{aligned}
S_{i}(t) & =C_{i}(t) / C_{\text {rock }}(t) * O_{\text {rock }}(t) \\
& =T_{i}^{\prime}(t) * O_{\text {rock }}(t)
\end{aligned}
$$

In this study, we selected CHY as the reference rock site. The soil type at this station is weathered granite that affects ground motions at periods shorter than $0.2 \mathrm{~s}$ but does not affect long-period ground motions considerably (e.g., Cho et al. 2004, 2006). During the calculation of $T^{\prime}(t)$ in Eq. 3 in the
Fig. 8 Goodness-of-fit factor $f$ at each station for the simulation using model A (left column) and model B (right column) on the northsouth and the east-west component. The contours with an interval of $0.2 \mathrm{~km}$ indicate the depth of the bedrock
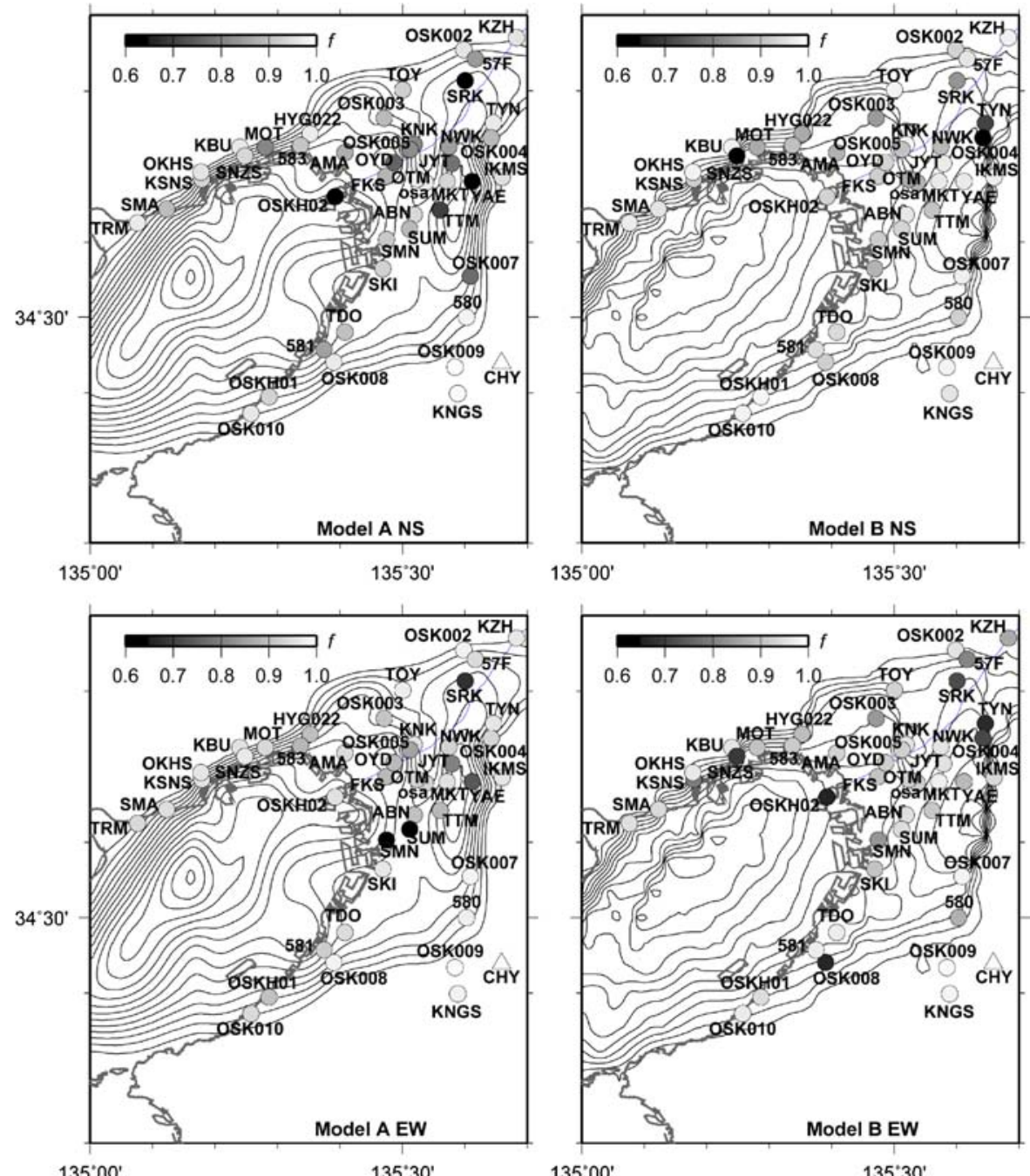

$135^{\circ} 00^{\prime}$

$135^{\circ} 30^{\prime}$ 
frequency domain, we added noise, whose amplitude is $5 \%$ of the peak amplitude of $C_{\text {rock }}(f)$ that stabilizes the deconvolution process.

\section{Estimation of $Q$ values}

Before comparing the synthetics with the observations for each model, we determined an appropriate $Q$ value for the sediment layers. Our calculation includes an attenuation formula proposed by Graves (1996) $Q=Q_{0}\left(T_{0} / T\right)$ where $Q_{0}$ is the $Q$ value at the reference period $T_{0}$.

Kawabe and Kamae (2005) conducted a parametric study of the $Q$ values for the sedimentary layers by comparing the ground motion durations of the synthetics and observations using the strong-motion data of an $\mathrm{M}_{\mathrm{JMA}} 5.7$ event that occurred at a depth of $40 \mathrm{~km}$ with the hypocenter located approximately $100 \mathrm{~km}$ from the Osaka basin. They demonstrated that the appropriate $Q$ values for the Osaka basin can be obtained as $Q=1 / 2-1 / 5 V_{\mathrm{S}}\left(V_{\mathrm{S}}\right.$ is in $\left.\mathrm{m} / \mathrm{s}\right)$ with a reference period of $1 \mathrm{~s}$. In this study, we used the data of an $\mathrm{M}_{\mathrm{JMA}} 6.4$ event with a shallower focal depth that transferred ground motion inside the basin rich in longer-period range. We first tried using $Q_{0}=1 / 3 V_{\mathrm{S}}$ with the reference period of $1 \mathrm{~s}$ and found the ground motion durations of the synthetics to be shorter than those of the observations. A reference period of $3 \mathrm{~s}$, compared to $1 \mathrm{~s}$ and $6 \mathrm{~s}$, produced the most appropriate ground motion durations and amplitudes without altering the relation between $Q_{0}$ and $V_{\mathrm{S}}$.
Fig. 9 Comparison of the pseudovelocity response spectra distributions for the period of $3,4,5$, and $6 \mathrm{~s}$ by model $\mathrm{A}$ and model $\mathrm{B}$. The upper panels represent the north-south component and the lower panels represent the east-west component. a $3 \mathrm{~s}, \mathbf{b} 4 \mathrm{~s}, \mathbf{c} 5 \mathrm{~s}$, and d $6 \mathrm{~s}$
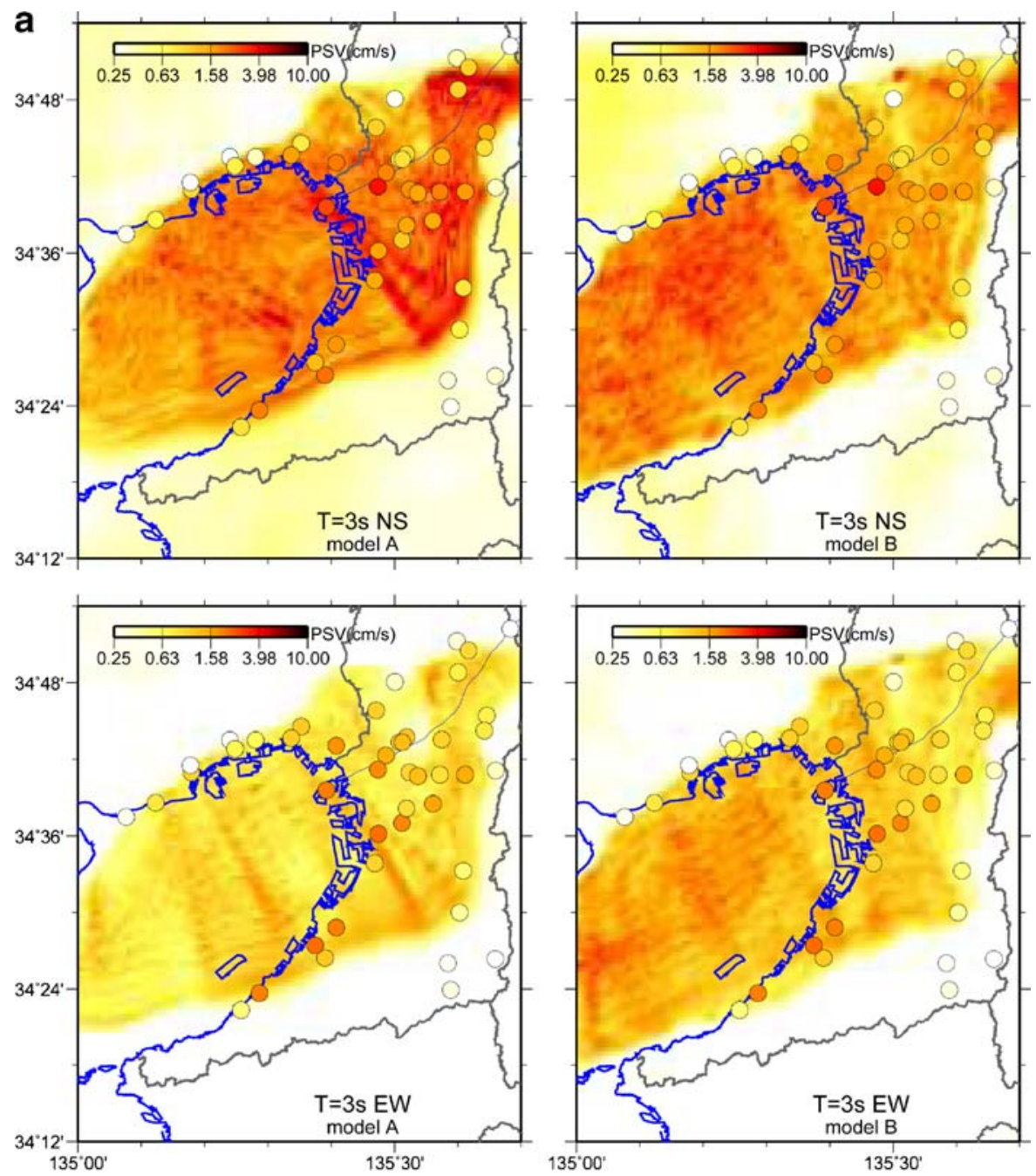
Figure 5 shows the comparisons of the synthetic ground motions with the observed ground motions with different reference periods at the sediment stations. We conducted our simulation with $Q_{0}=1 /$ $3 V_{\mathrm{S}}$ and the reference period of $3 \mathrm{~s}$. This examination suggests that the difference of the predominant period in observed ground motions between Kawabe and Kamae (2005) and ours caused the difference in the reference period of $Q$ values for ground motion simulations in Graves' (1996) attenuation formula.

\section{Comparison of waveform simulation results}

We conducted numerical simulations of the two models and used the observed ground motion at
CHY to obtain the synthetic ground motions for each basin site following Eq. 3. Figure 6 shows some examples of the synthetic and the observed velocity waveforms. The waveforms are bandpass filtered at 3-20 s. The synthetic waveforms at $\mathrm{CHY}$ are not exactly identical to the observed waveforms because the modification described above is adopted in the process of deconvolution while calculating the transfer function. At KNGS, another rock site station, the synthetic waveforms show very good agreement with the observed waveforms. At stations FKS and SKI, located near the central part of the basin where the ground motions are greatly amplified, the waveforms including the later phases are reasonably well reproduced by both the models. Stations YAE and TYN are located near the eastern edge of the basin where the

Fig. 9 (continued)
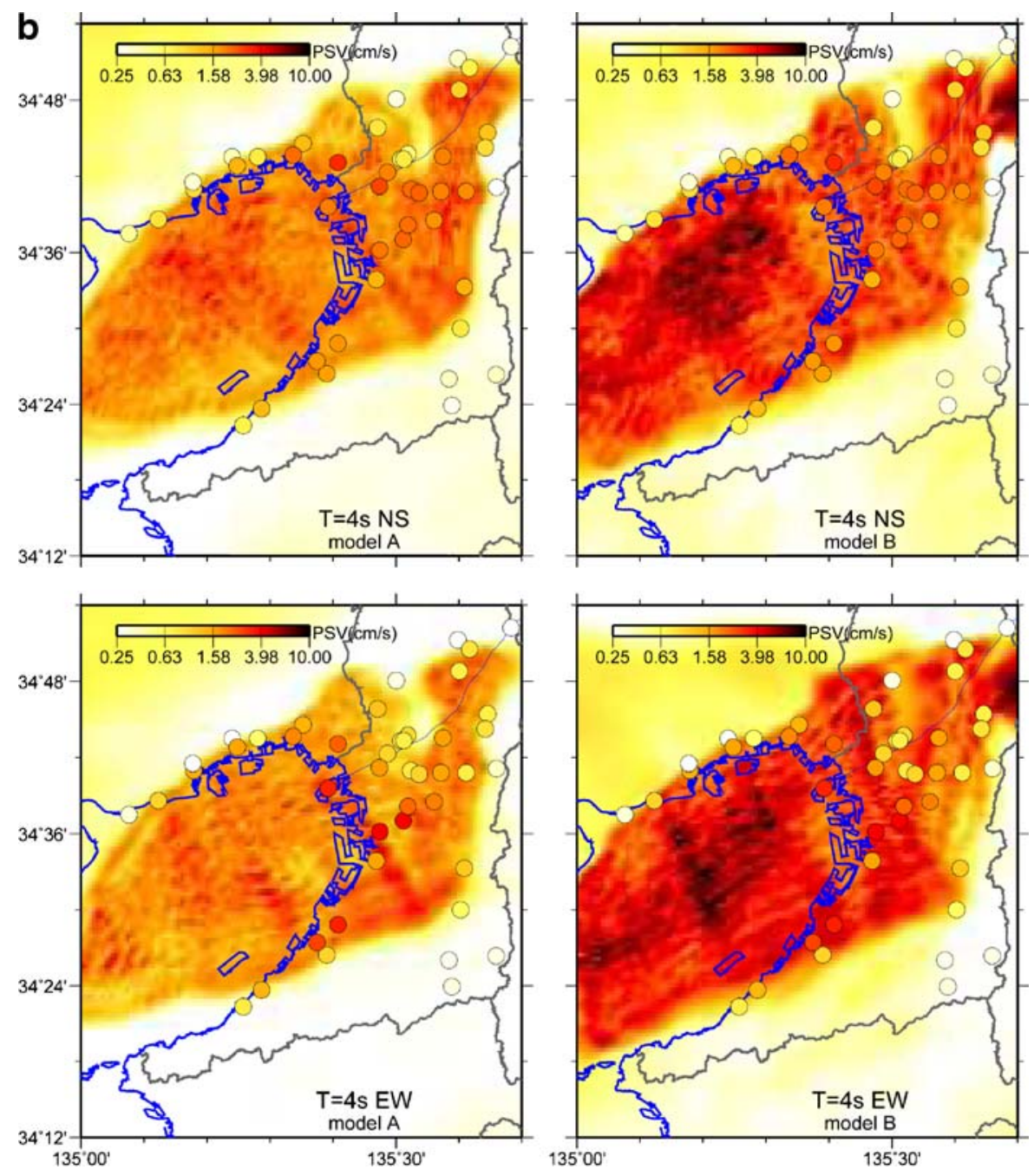
bedrock depth varies steeply toward the Ikoma hills. The north-south component of the synthetic waveforms of model A is overestimated at YAE. On the other hand, at TYN, the synthetic waveforms of model B are overestimated. Stations MOT and SMA are located in Kobe City beside the Rokko Mountains that form the northern edge of the basin. At MOT, the synthetic waveforms of model A are greatly amplified in the later phases, while those of model B underestimate the horizontal components. At SMA, the amplitudes of the synthetics are on the whole larger than those of the observations.

To see the reproducibility of the predominant periods in detail, we calculated the pseudovelocity response spectra $(\mathrm{pSv})$ at $5 \%$ of the synthetic and observed waveforms. Figure 7 shows the comparison of the $\mathrm{pSv}$ at the eight stations introduced in Fig. 6. At KNGS, FKS, and SKI, the pSv fit is relatively good; however, the predominant periods of the synthetics of model B are slightly shorter than those of the observations at FKS and SKI. At the stations near the eastern edge of the basin, YAE and TYN, the pSv fit is not as good. The synthetic $\mathrm{pSv}$ is overestimated by model A at YAE and by model B at TYN, respectively, as seen in the waveforms (Fig. 6), and their peak periods are different from those of the observed pSv. At MOT, major discrepancies can be observed between the observation and the synthetics of both models. At SMA, although the pSv fit is good at periods of $5 \mathrm{~s}$ and longer, the synthetics of both models overestimate the observations near the peak periods. The comparison of the $\mathrm{pSv}$ at all the 47 stations is shown in the Appendix.

Fig. 9 (continued)
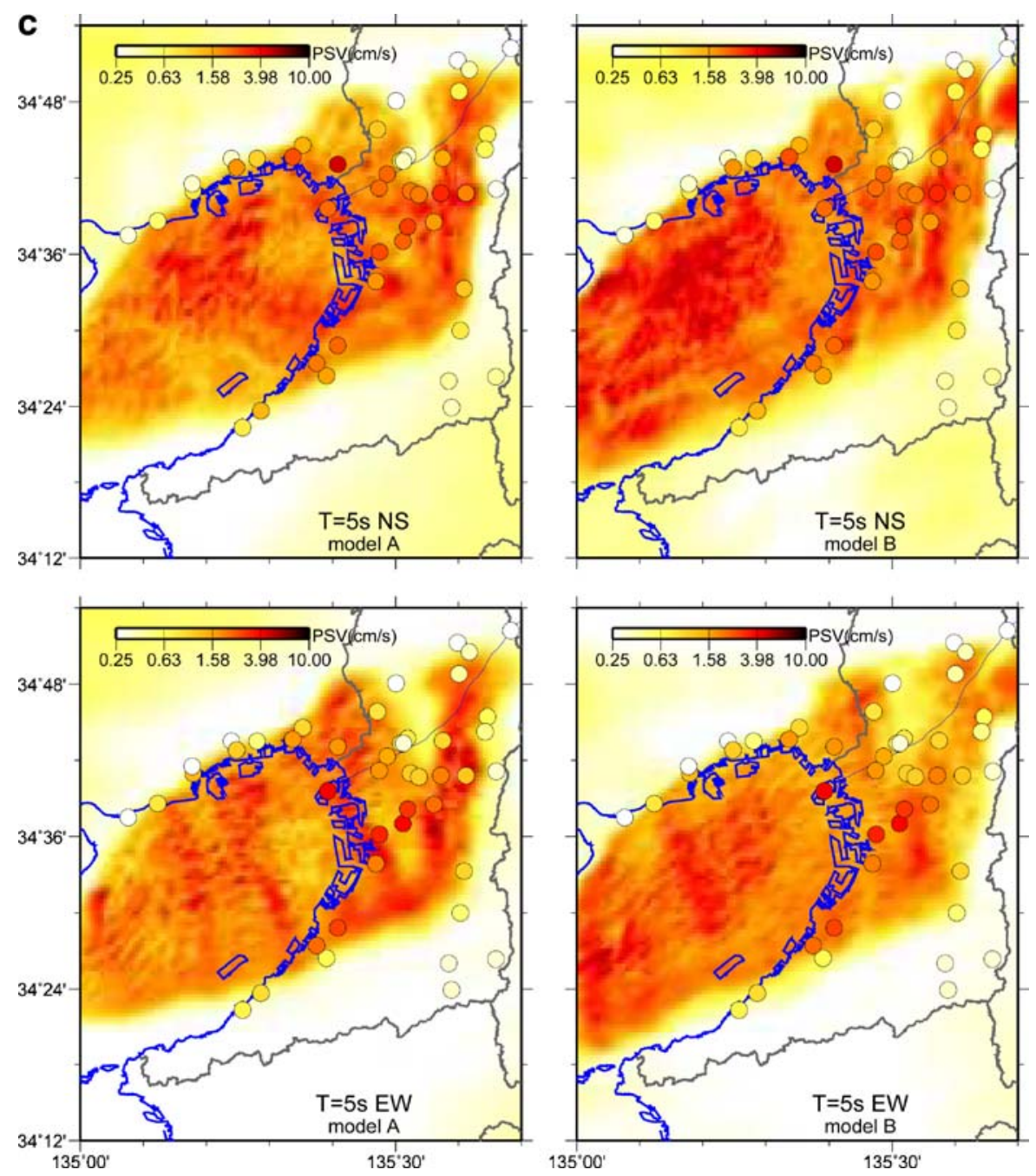
Fig. 9 (continued)
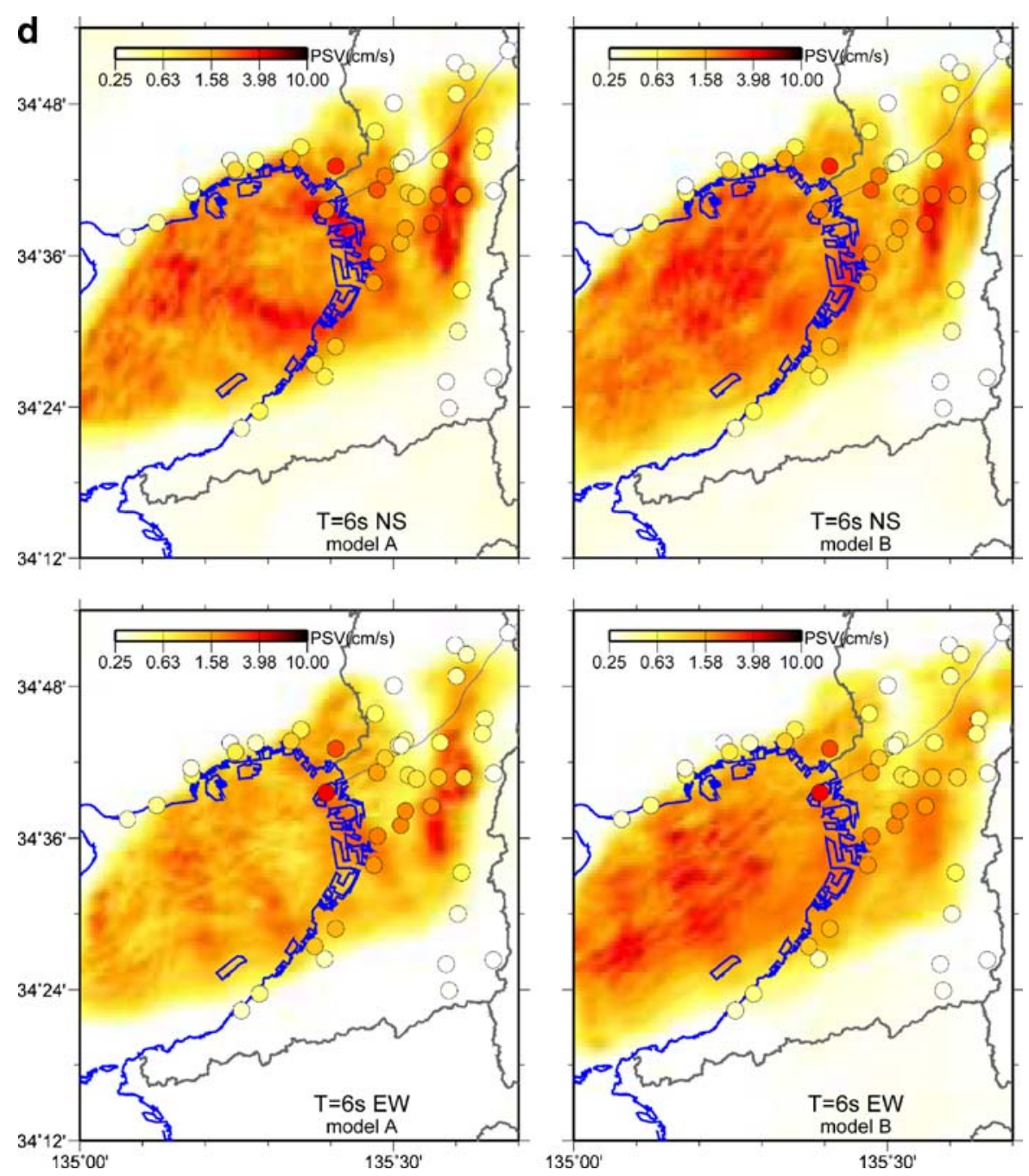

Assuming the $\mathrm{pSv}$ to be a representation of the ground motion characteristics at the period range of 3-20 s at each station, we applied a goodness-of-fit factor to the $\mathrm{pSv}$ to evaluate the ability of our simulations to reproduce the long-period ground motion characteristics. The goodness-of-fit factor $f$ is given by the following equation (e.g., Pitarka et al. 2004):

$f=2 \frac{\int p(T)_{\mathrm{obs}} p(T)_{\mathrm{syn}} \mathrm{d} T}{\int p(T)_{\mathrm{obs}}^{2} \mathrm{~d} T+\int p(T)_{\mathrm{syn}}^{2} \mathrm{~d} T}$

where $p(T)_{\mathrm{obs}}$ and $p(T)_{\mathrm{syn}}$ are the observed and synthetic $\mathrm{pSv}$ at each period. While Pitarka et al. (2004) used this factor for the time-domain wave- forms, we used it for $\mathrm{pSv}$ comparisons. The value of $f$ ranges from 0 to 1 ; the better the fit, the closer $f$ is to 1. The factor $f$ calculated at each station from 3 to $20 \mathrm{~s}$ is shown on a map with bedrock depth contours in Fig. 8. The value of $f$ is $>0.6$ at most stations, and it is $\geq 0.8$ at many stations; however, it is $<0.6$ at a few particular stations in the case of either of the models. There are noticeable differences in the value of $f$ for the models at the stations located along the eastern and northern edges of the basin, such as SRK, TYN, OSK004, YAE, and OSK007 where the bedrock depth contours of the models are not similar to each other. OSKH02 is another station that shows a major difference in its value of $f$ and also in its $\mathrm{S}$ wave velocity profiles (Fig. 4), although it is located in the central part of the basin. In addition to those stations, 
the value of $f$ is as low as $0.5-0.6$ for model $\mathrm{A}$ in the east-west component at stations SMN and SUM, both located in the central part of the basin adjoining each other. The S wave velocity profiles at station SUM are shown in Fig. 4; there is little difference in the profiles for both models. This suggests that the longperiod ground motion characteristics inside the basin cannot be explained only by the 1-D underground velocity structures beneath the stations.

The comparisons of the spatial $\mathrm{pSv}$ distributions at periods of $3,4,5$, and $6 \mathrm{~s}$ by model $\mathrm{A}$ and model $\mathrm{B}$ are shown in Fig. 9, together with the observed $\mathrm{pSv}$ values at each station at the corresponding periods. The simulation results of the two models show some discrepancy at shorter periods ( 3 and 4 s), whereas they are more similar to each other and show better agreement with the observations at longer periods ( 5 and $6 \mathrm{~s}$ ). The larger $\mathrm{pSv}$ values vary with the period, which suggests complex effects of the underground basin structure on the pSv. At the period of $6 \mathrm{~s}$, the $\mathrm{pSv}$ are remarkably large not only in the Osaka bay area region but also in the eastern Osaka region (the region between the Uemachi elevation and Ikoma hill). Moreover, the $\mathrm{pSv}$ of the north-south component is larger than that of the east-west component at the eastern Osaka region that coincides with the observed characteristics that were pointed by Iwaki and Iwata (2006). These characteristics are of great importance for estimating long-period ground motions caused by large earthquakes that are likely to occur in the future.

\section{Concluding remarks}

To evaluate the applicability of the Osaka basin velocity structure models proposed by Kagawa et al. (2004a) and Horikawa et al. (2003) to long-period ground motion estimation, we compared the simulation results of the two models with the observations that are rich in later arrivals of the long-period ground motions, in velocity waveforms, and in pseudovelocity response spectra. In this paper, we proposed the use of a reference rock site for evaluating the wave propagation characteristics inside the basin. Both model A and model B reproduced the observations fairly well not only on the response spectra but also on the waveforms at most stations inside the basin. At some stations, especially where the bedrock depth varies sharply, there were noticeable discrepancies in the simulation results of model A and model B. The basin shapes of the two models were significantly different around such stations, suggesting that the current basin models are not describing certain parts of the complicated structure near the basin edge reliably enough. Moreover, this shortcoming might have been responsible for the discrepancies in the simulation results at certain stations in the central part of the basin. We conclude that the superiority of one model over another cannot be determined at the present and that an improvement in the models based on ground motion simulations is necessary, especially in the region along the basin edge.

Acknowledgements We would like to thank CEORKA, NIED (K-NET and KiK-net), JMA, Osaka City Waterworks Bureau, and the project of 10 electric companies for providing the strong motion data. The hypocenter information was provided by JMA and the moment tensor by F-net of NIED. We sincerely appreciate the significant efforts put in by Takao Kagawa and Haruo Horikawa and their group members toward the construction of the underground velocity structure models, and thank them for letting us use the models. Comments by Kimiyuki Asano helped us improve the manuscript. Comments by two reviewers and Prof. Kim Olsen, the guest editor, were also useful in improving the manuscript. The Generic Mapping Tools (Wassel and Smith 1998) was used to draw all the figures in this paper. This study is supported by Grant-in-Aid for Scientific Research (B) (No. 18310123, P.I.: T. Iwata) and Scientific Research (A) (No. 19201034, P.I.: K. Koketsu).

\section{Appendix}

We present a comparison of the pseudovelocity response spectra at all 47 stations obtained from the observed and synthetic waveforms that were bandpass filtered at 3-20 s with 5\% damping in Fig. 10 for the EW component (a) and the NS component (b).

Fig. 10 Comparison of the pseudovelocity response spectra $(h=5 \%)$ for the observation (black line) and the synthetics using model A (red line) and model B (blue line) at all 47 stations on $\mathbf{a}$ the north-south component and $\mathbf{b}$ the east-west component 
a

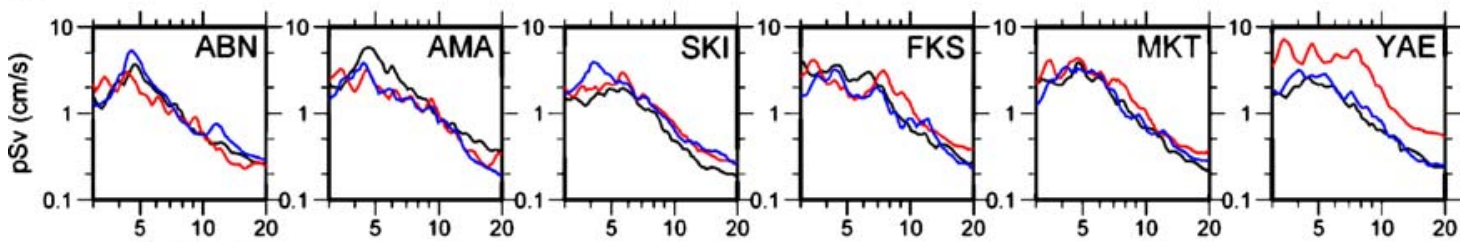
period (sec)
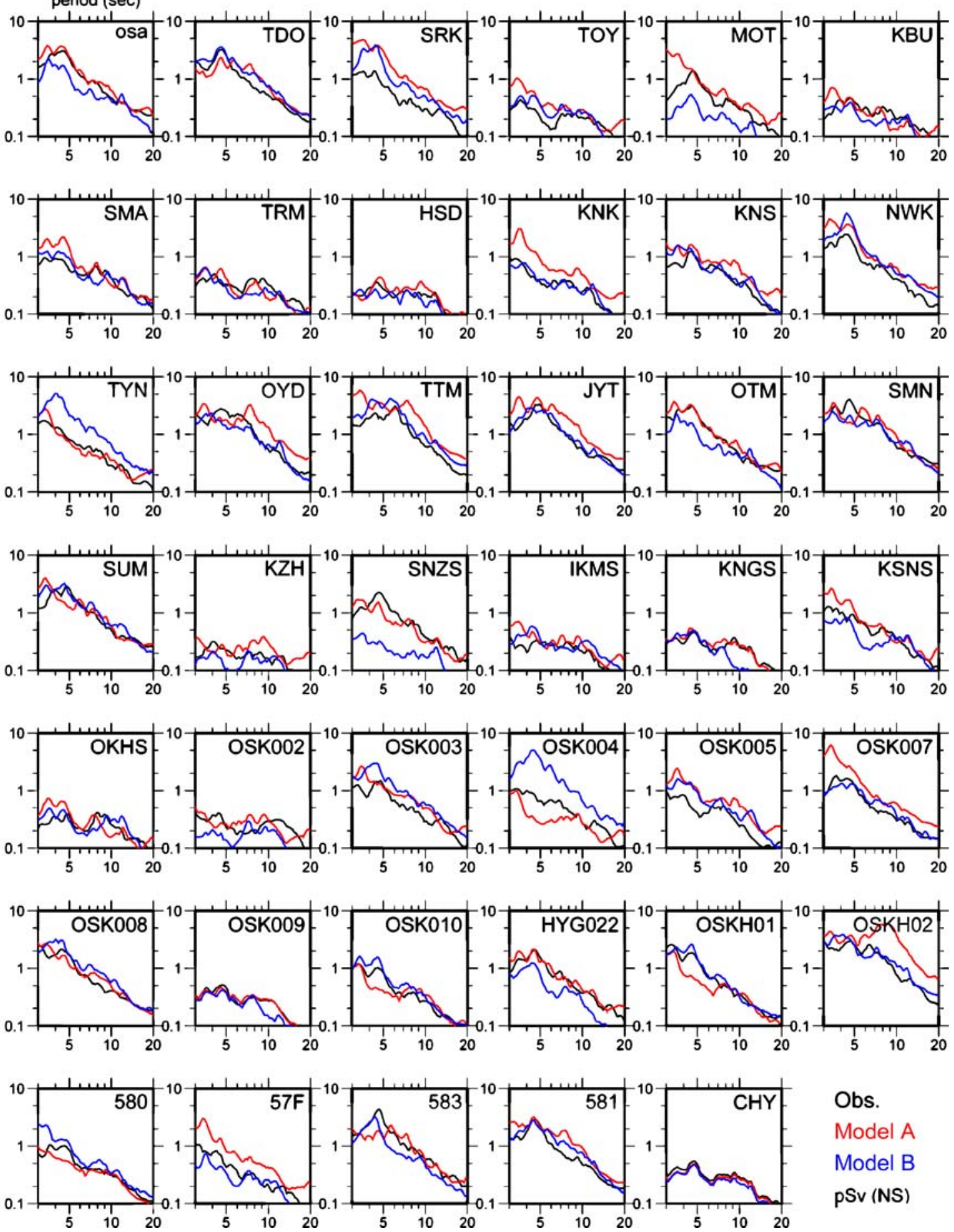

Obs.

Model A

Model B

pSv (NS) 

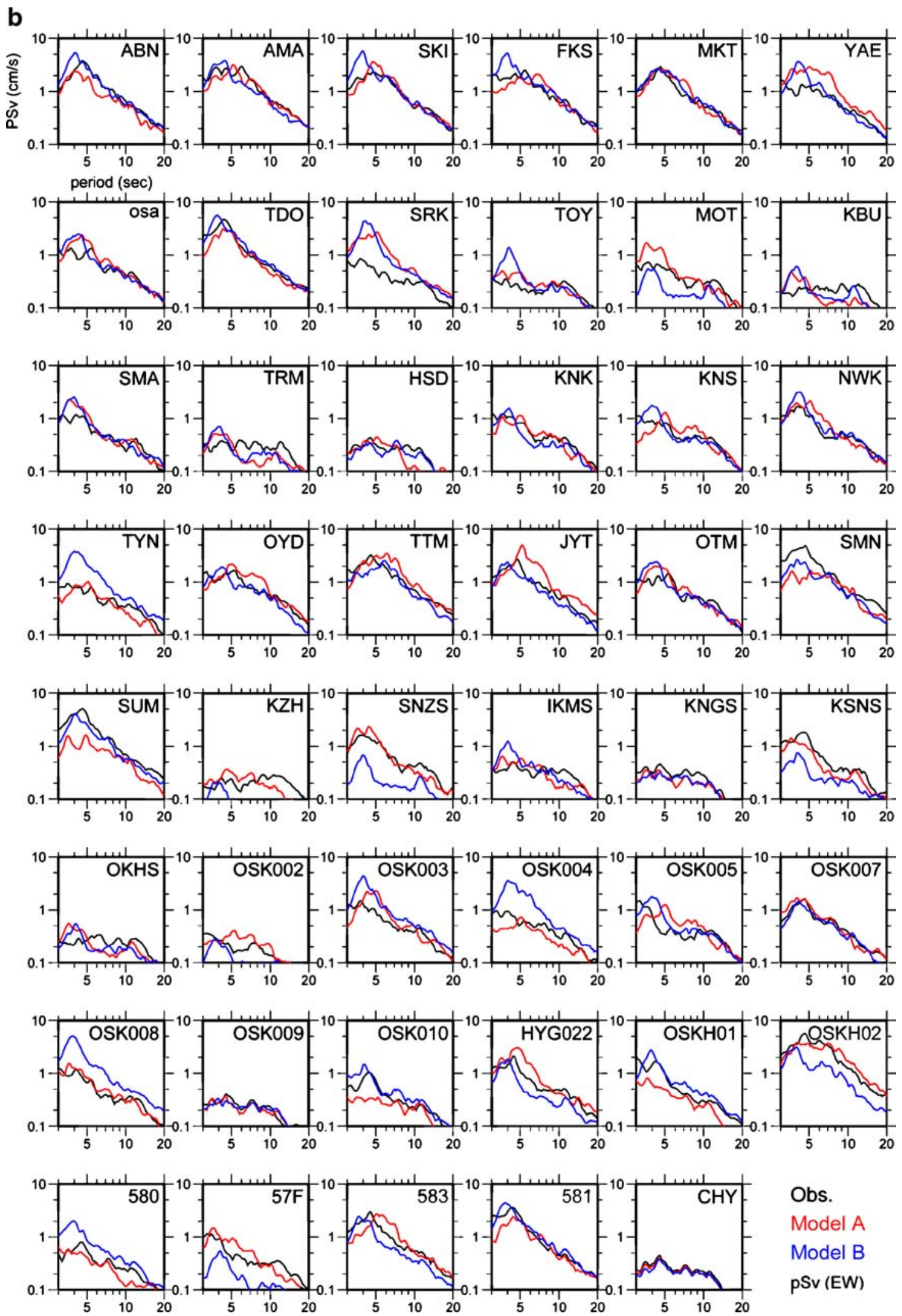

Obs.

Model A

Model B

pSv (EW) 
Fig. 10 (continued)

Open Access This article is distributed under the terms of the Creative Commons Attribution Noncommercial License which permits any noncommercial use, distribution, and reproduction in any medium, provided the original author(s) and source are credited.

\section{References}

Aoi S, Obara K, Hori S, Kasahara K, Okada Y (2001) New Japanese uphole/downhole strong-motion observation network: KiK-net. Seismol Res Lett 72:239

Bai L, Kawasaki I, Zhang T, Ishikawa Y (2006) An improved double-difference earthquake location algorithm using sP phases: application to the foreshock and aftershock sequences of the 2004 earthquake offshore of the Kii peninsula, Japan (Mw=7.5). Earth Planets Space 58:823-830

Cho I, Tsurugi M, Iwata T, Kagawa T, Zhao B (2004) Modeling of the spectral amplitude characteristics at the strong motion observation sites in the Osaka basin, Japan. Proc. 13th World Conf. Earthq. Eng., Vancouver, BC, Canada, pp 825

Cho I, Tsurugi M, Kagawa T, Iwata T (2006) Modeling of deep sedimentary velocity structure for evaluation of broadband strong ground motions: Site-amplification spectra in Osaka sedimentary basin. J Japan Assoc Earthq Eng 6(4):113132 (in Japanese with English abstract)

Gassmann F (1951) Elastic waves through a packing of spheres. Geophysics 16:673-685

Graves RW (1996) Simulating seismic wave propagation in 3D elastic media using staggered-grid finite differences. Bull Seismol Soc Am 86:1091-1106

Horikawa H, Mizuno K, Satake K, Sekiguchi H, Kase Y, Sugiyama Y, Yokota H, Suehiro M, Pitarka A (2002) Three-dimensional subsurface structure model beneath the Osaka Plain. Annual Report on Active Fault and Paleoearthquake Researches, Geological Survey of Japan/AIST 2:291-324 (in Japanese with English abstract)

Horikawa H, Mizuno K, Ishiyama T, Satake K, Sekiguchi H, Kase Y, Sugiyama Y, Yokota H, Suehiro M, Yokokura T, Iwabuchi Y, Kitada N, Pitarka A (2003) A three-dimensional model of the subsurface structure beneath the Osaka sedimentary basin, southwest Japan, with fault-related structural discontinuities. Annual Report on Active Fault and Paleoearthquake Researches, Geological Survey of Japan/AIST 3:225-259 (in Japanese with English abstract)

Iwata T, Asano K (2005) Long-period ground motion during the 2004 earthquake sequence off the Kii peninsula and the Tokai District. Journal of the Seismological Society of Japan 58:273-279 (in Japanese with English abstract)

Iwaki A, Iwata T (2006) Long period ground motion characteristics of the 2004 Off Kii-Peninsula earthquakes in Osaka basin. Abstracts of Japan Geoscience Union Meeting S116-P007

Iwata T, Kagawa T, Petukhin A, Onishi Y (2006) Basin and crustal structure model for strong motion simulation in Kinki, Japan. Proc. 3rd Int. Symp. Effect of Surface
Geology on Seismic Motion, Grenoble, France, pp 435442

Iwata T, Kagawa T, Petukhin A, Onishi Y (2008) Basin and crustal velocity structure models for the simulation of strong ground motions in the Kinki area, Japan. J Seismol DOI 10.1007/s10950-007-9086-7

Kagawa T, Sawada S, Iwasaki Y, Nanjo J (1993) Modeling the deep sedimentary structure in the Osaka basin. Proc. 22nd JSCE Earthquake Engineering Symposium, pp 199-202 (in Japanese)

Kagawa T, Irikura K, Takemura M (1998a) Estimation of strong ground motion-present status and future. Journal of the Seismological Society of Japan 51:339-454 (in Japanese with English abstract)

Kagawa T, Sawada S, Iwasaki Y, Nanjo J (1998b) $S$-wave velocity structure model of the Osaka sedimentary basin derived from microtremor array observations. Journal of the Seismological Society of Japan 51:31-40 (in Japanese with English abstract)

Kagawa T, Zhao B, Miyakoshi K, Irikura K (2004a) Modeling of 3D basin structures for seismic wave simulations based on available information on the target area: case study of the Osaka basin. Bull Seismol Soc Am 94:1353-1368

Kagawa T, Iemura H, Irikura K, Toki K (2004b) Strong ground motion observation by the Committee of Earthquake Observation and Research in the Kansai Area (CEORKA). J Japan Assoc Earthq Eng 4(3):128-133

Kato K, Yamazoe M, Takemura M (2001) Azimuth estimation of KiK-net borehole seismometers distributed in Cyugoku and Shikoku regions, Japan - on the basis of strong motion records from the Tottoriken-seibu and the Geiyo earthquakes. Journal of the Seismological Society of Japan 54:421-429 (in Japanese with English abstract)

Kawabe H, Kamae K (2005) Estimation of $Q$ value for long period ground motion simulation in Osaka basin. Prog. Abst. 2nd Int. Workshop on Strong Ground Motion Prediction and Earthquake Tectonics in Urban Areas, Tokyo, pp 155-158

Kinoshita S (1998) Kyoshin Net (K-NET). Seismol Res Lett 69:309-332

Koketsu K, Higashi S (1992) Three-dimensional topography of the sediment/basement interface in the Tokyo Metropolitan area, central Japan. Bull Seismol Soc Am 82: 2328-2349

Koketsu K, Hatayama K, Furumura T, Ikegami Y, Akiyama S (2005) Damaging long-period ground motions from the 2003 Mw 8.3 Tokachi-oki, Japan, earthquake. Seismol Res Lett 76:67-73

Miyake H, Koketsu K (2005) Long-period ground motions from a large offshore earthquake: The case of the 2004 off the Kii peninsula earthquake. Earth Planets Space 47: 203-207

Miyakoshi K, Kagawa T, Sawada S, Echigo T, Horie Y (1997) Modeling the deep sedimentary structure in the Osaka basin (2). Proc. 24th JSCE Earthquake Engineering Symposium, pp 33-36 (in Japanese)

Miyakoshi K, Kagawa T, Zhao B, Tokubayashi M, Sawada S (1999) Modeling the deep sedimentary structure in the Osaka basin (3). Proc. 25th JSCE Earthquake Engineering Symposium, pp 185-188 (in Japanese) 
Pitarka A (1999) 3D elastic finite-difference modeling of seismic motion using staggered grids with nonuniform spacing. Bull Seismol Soc Am 89:54-68

Pitarka A, Graves R, Somerville P (2004) Validation of a 3D velocity model of the Puget Sound Region based on modeling ground motion from the 28 February 2001 Nisqually earthquake. Bull Seismol Soc Am 94:1670-1689
Wassel P, Smith WHF (1998) New, improved version of the Generic Mapping Tools released. EOS Trans Am Geophys Union 79:579

Yamada N, Iwata T (2005) Long-period ground motion simulation in the Kinki area during the $\mathrm{M}_{\mathrm{J}} 7.1$ foreshock of the 2004 off the Kii peninsula earthquakes. Earth Planets Space 57:197-202 